\title{
John $\mid$ Making Buildings \\ Sharp \\ 30 June - 21 November 2001, Middlesbrough, Manchester, Aberystwyth, United Kingdom.
}

This exhibition, Making Buildings, now touring the UK, features the work of sixteen groups or individuals covering a range of architects, construction companies and craftspeople to present the way a building is crafted. It is a varied exhibition which is meant to show how an "architect's vision can only be brought to life by the skills of craftspeople". It does more than this, in that it is obvious from the range of ideas that there is a great deal of mathematics involved also. The forms presented show that there are people who are going beyond the boring cubic structures present in so many forms of modern architecture. The following review shows a selection of the ideas which most distinctly show a beauty of mathematical form.

Too often when mathematics and architecture are discussed the emphasis is on very precise mathematical relationships, using definite proportions such as the Golden Section. The ideas in this exhibition show that there are many ways to express mathematics in architecture without recourse to such rigidity and that collaboration with craftspeople who have an idea of form which is much more plastic. The materials used also add to this effect in a way which is also ignored when discussing the shape and form.

Architects and craftspeople should both feel at home in the exhibition, but it is an eye opener for anyone not fitting into either discipline. It should also alert architects to look at the possibility of looking to crafts and their practitioners for both inspiration and further collaboration.

The following few images and descriptions show the most geometric forms, concentrating more on the ones closest to being structures. Some other ideas (such as the Geodesic sphere shown last), although geometrically inspired, were not developed into buildings.

\section{Tono Mirai’s Nest}

This structure "explores the possibility of spiritual space in architecture" and is made of straw, steel, mud and clay, sand and lime. This is a structure which would make an ideal play house for children. Even without the spiral structure of the

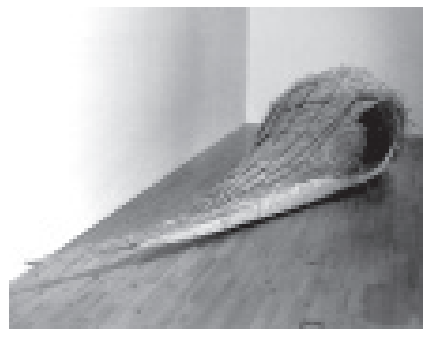

Figure 1

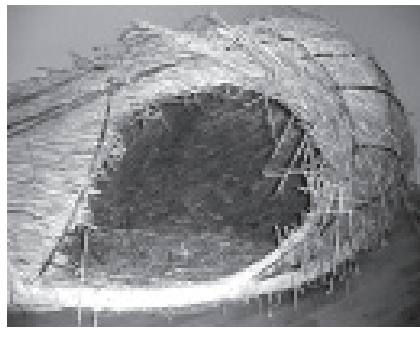

Figure 2 
way the straw and support structures fits around the space, it is a very living form (Figures 1 and 2).

\section{Edward Cullinan Architects' Visitor Centre Building}

This is a model based on a building for a visitor centre at an open air museum (Figure 3). The overall image of the support structure looks like another living form. The way it is held together (shown in Figure 4) is very geometric. Although the roofing would hide this externally (Figure 5), it would still be an exciting building from the inside both because of the shape and the way the grid curves when looked at from within.

\section{Vortex by Usida Findlay Architects with Lee Dalby}

This structure is described in the leaflet that accompanies the exhibition as a "circular bamboo structure" (Figures 6 and 7). The bamboo is joined at the end to give the lengths required. It is in fact an interesting spiral space which is not unlike the shell or other natural forms using a spiral. Figure 7 shows its simplicity of construction, and how the rotation required for the spiral is achieved. It could be covered and be opened and closed in response to the weather, but as you walk into the space it is very inviting. Lee Dalby (helped by Julia Thompson) is a basket maker collaborating with the architects.

\section{Geodesic Sphere by Cowley Structural Timberworks}

This does not seem to be new, as anyone who knows the work of Leonardo da Vinci will recognise. It is not in fact a geodesic sphere, but an icosahedron (Figure 8). As such, it looks out of place in an exhibition of buildings when it is hung from the ceiling. It is made of laminated wood, and what the company says is their patented "shearlock connectors" are designed for neat, efficient joints in timber. Figure 9 shows the joint, and if you were to look closely, you would see that there are what appear to be grub screws going out into the struts. Even though I do not see it as quite fitting in as a building, it is a fine piece of craftsmanship.

\section{Exhibit information}

30 June to 5 August 2001: Centre North East

(Middlesbrough Museums Service)

Albert Road, Middlesbrough

Contact: Julia Bell, Curator. Telephone 01642358139

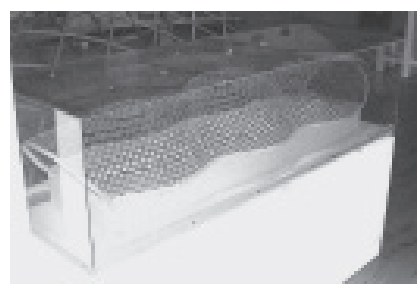

Figure 3

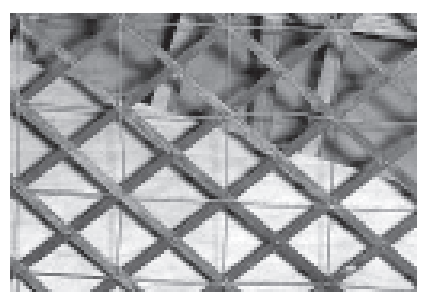

Figure 4

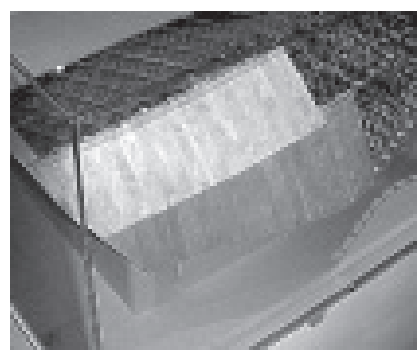

Figure 5

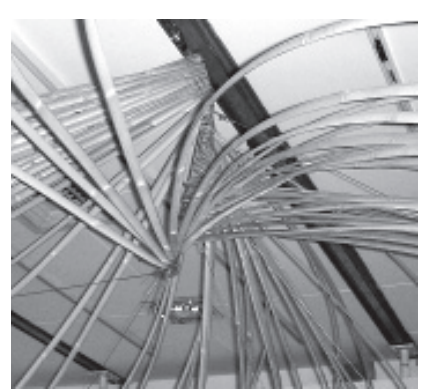

Figure 6

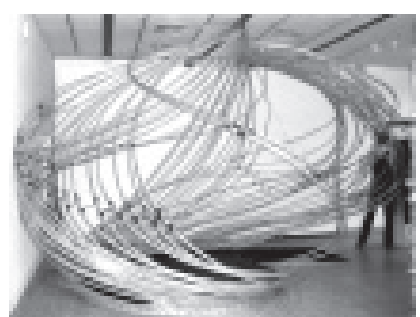

Figure 7 


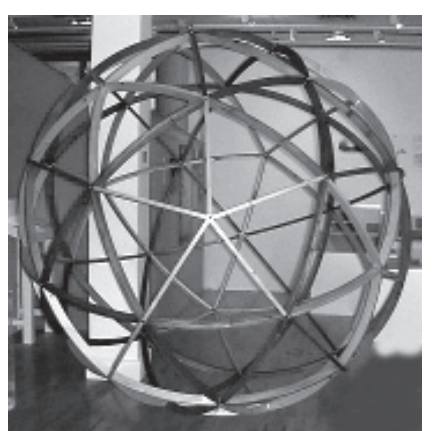

Figure 8

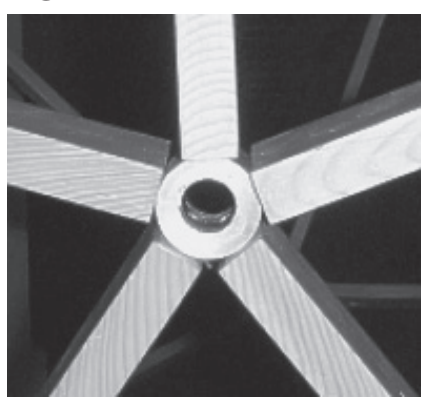

Figure 9
18 August to 29 September 2001: Turnpike Gallery Civic Square, Leigh Greater Manchester WN7 1EB

Contact: Kerry Moogan Gallery Officer.

Telephone 01942404469

6 October to 21 November 2001: Aberystwyth Arts

\section{Centre}

Penglais, Aberystwyth SY23 3DE

Contact: Eve Ropek. Telephone 01970622882

\section{About the reporter}

John Sharp has researched and taught Geometry and Art for over 20 years in Adult Education in and around London. He is the illustrator of David Wells's Penguin Dictionary of Curious and Interesting Geometry and has written his own book on modelling geometrical surfaces called Sliceforms, some of which are in the "Strange Surfaces" exhibit in the Science Museum in London. 